\title{
Quem escreve sobre história do Brasil na Alemanha?
}

\author{
Who writes about Brazilian history in Germany?
}

\author{
René E. Gertz \\ gertz@pucrs.br \\ Professor titular \\ Pontifícia Universidade Católica do Rio Grande do Sul \\ Av. Ipiranga, 6681 \\ 90619-900 - Porto Alegre - RS \\ Brasil
}

\section{Resumo}

Após ter publicado, em 1995, um levantamento da produção sobre história do Brasil na Alemanha no período de 1980 a 1995, busco neste artigo retomar o tema, concentrando, agora, a atenção nos anos de 1995 a 2014. Como da vez anterior, esta é uma tentativa de avaliar o interesse de pesquisadores alemães pelo tema. Para tanto, fiz um arrolamento dos principais centros universitários que se dedicam a estudos sobre a América Latina, e busquei examinar que importância se atribui neles a temas da história brasileira, estabelecendo, na medida do possível, comparações com o interesse dedicado à história de outros países do subcontinente. Os dados mostraram que, apesar de um claro aumento de interesse em ao menos uma universidade, a situação não se modificou de forma substancial em relação ao período anterior. Mesmo assim, foi possível registrar algumas produções acadêmicas relevantes, cobrindo um leque diversificado de aspectos da história brasileira.

Alemanha; História do Brasil; Historiografia alemã.

\section{Abstract}

After undertaking in 1995 an analysis of the academic production about Brazilian history in Germany from 1980 to 1995 , I intend in this article to resume work in the subject, with a focus on the period from 1995 to 2014. As before, this is an attempt to assess the interest of German researchers in this theme. The research listed the main university centers undertaking Latin-American studies and sought to examine what importance they attach to issues of the Brazilian history. As much as possible, comparisons were also made with the level of interest ascribed to the history of other countries of the subcontinent. The data shows that, despite an increase in the interest in at least one university, the situation has not changed much in comparison to the previous period. Still, it was possible to record some relevant academic productions covering a wide range of aspects of Brazilian history.

\section{Keywords}

Germany; Brazilian history; German historiography.

Recebido em: 21/1/2015

Aprovado em: 13/3/2015 


\section{História do Brasil na Alemanha}

Em artigo de 1995, analisou-se a produção sobre história do Brasil na Alemanha, de 1980 a 1994 (GERTZ 1995). ${ }^{1}$ Constatou-se que, enquanto temas brasileiros eram abordados por outras áreas das Ciências Humanas (Ciência Política, Economia, Sociologia) e da Literatura, a Ciência Histórica alemã mostrava maior interesse por outros países latino-americanos. Não foi possível descobrir os motivos, mas, talvez, o fato de que, na Alemanha, a língua espanhola esteja mais difundida que a portuguesa representasse um deles. Além disso, pode-se imaginar que se o Brasil é visto como país exótico na atualidade, outros países possuem uma história mais cativante - ainda que esse argumento seja, necessariamente, parcial, pois, se válido para o México (país com maior número de referências), Peru e América Central, não se aplica à Argentina e ao Chile, países aos quais também foi dedicado número significativo de estudos.

Levantamento publicado em 2012 por dois membros do Instituto Ibero-Americano de Berlim constatou que, na área de História, o México continua despertando o maior interesse nas pesquisas sobre a América Latina na Alemanha, seguido pela Argentina. Os números dos autores indicam que o Brasil estaria em terceiro lugar (seguido do Chile) (GÖBEL; BIRLE 2012, p. 26). Mesmo assim, admitem que recebe "muy poca atención en la investigación si tenemos en cuenta su tamaño y importancia" (GÖBEL; BIRLE 2012, p. 52). ${ }^{2}$

Em estada recente na Alemanha, fez-se uma tentativa de levantamento similar ao de 1995, agora sobre o período 1995 a 2014. ${ }^{3}$ Com uma permanência mais breve que a anterior, não foi possível levantar dados para uma comparação sistemática entre a quantidade de trabalhos dedicados à história do Brasil e à de outros países latino-americanos. ${ }^{4}$ Mas, na tentativa de localizar aquilo que foi escrito sobre o Brasil, tem-se a nítida impressão de que não ocorreu uma mudança radical, nos últimos 20 anos, na comparação com os 15 anos anteriores. De qualquer forma, naquilo que segue, se tentará dar uma ideia da produção historiográfica alemã sobre o Brasil. Para tanto, se fará referência aos principais centros universitários que se dedicam à América Latina, para uma brevíssima avaliação - sem qualquer pretensão de aprofundamento.

Pode-se antecipar uma constatação já feita no levantamento de 1995: estudos classificados como de história do Brasil não foram produzidos apenas em instituições universitárias de Ciências Humanas, mas também em lugares que têm pouco a ver com essa área. Referiu-se, por exemplo, um estudo histórico sobre doenças, hospitais, seguro-saúde na colônia Blumenau, em Santa Catarina, no século XIX, apresentado como tese de doutorado numa faculdade

\footnotetext{
${ }^{1} \mathrm{O}$ texto está disponível em: http://www.seer.ufrgs.br/index.php/anos90/article/view/6157/3651. Acessado em: 04 jan. 2015.

2 Os autores sugerem que o interesse de pesquisadores alemães pelo México não deriva só de uma opção pessoal: "También como socios de cooperación son las instituciones mexicanas las que desempeñam con diferencia el papel más importante para los científicos alemanes" (GÖBEL; BIRLE 2012, p. 52-53).

3 Essa estada ocorreu em 2014, como parte de um intercâmbio PROBRAL I (CAPES/DAAD), sob o tema "Circulação de saberes entre Brasil e Europa: atores e ideias desde a globalização oitocentista até o presente", entre PUCRS e Universidade Livre de Berlim.

${ }^{4}$ Göbel e Birle (2012, p. 16-26) apresentam tabelas com vários indicadores. Este artigo, porém, foi desenvolvido de forma independente, sem a pretensão de confirmar ou refutar dados e opiniões dos dois autores.
} 
de medicina (GERTZ 1995, p. 90). ${ }^{5}$ Situações semelhantes ocorreram de 1995 a 2014. Além disso, mais uma vez, não é desprezível o número de trabalhos desenvolvidos por brasileiros, em universidades alemãs.

\section{Os principais centros universitários que se dedicam à América Latina}

Uma das universidades alemãs em que estudos latino-americanos possuem longa tradição é a de Colônia, com uma cátedra para História Ibérica e Latino-Americana, desde 1961. Ali se fundou, em 1964, uma revista dedicada ao tema, o Jahrbuch für Geschichte von Staat, Wirtschaft und Gesellschaft Lateinamerikas, mais tarde rebatizada para Jahrbuch für Geschichte Lateinamerikas. O departamento é, provavelmente, o maior da Alemanha, pois reúne quatro catedráticos. No entanto, nenhum deles apresenta produção que denote preocupação específica e continuada com a história brasileira.

Barbara Potthast se dedica, sobretudo, a estudos sobre família e gênero, na América Latina, mas suas referências são Argentina, Paraguai e América Central. Holger Meding produziu trabalhos importantes sobre influência nazista na Argentina, e mais recentemente volta-se para aspectos da história centro-americana. Michael Zeuske estuda a escravidão, mas com foco no Caribe. Por fim, o interesse principal da catedrática-júnior Stefanie Gänger é a história da Arqueologia e dos vestígios deixados pelas culturas pré-colombianas, sobretudo no mundo andino, e, mais recentemente, história das ciências. Entre os assistentes, ${ }^{6}$ duas realizaram pesquisas sobre o Brasil, mas não se trata propriamente de história, e sim de temas contemporâneos, como a tese em preparação de Bea Wittger sobre "Cidadania e gênero no Brasil: mulheres na luta por espaço urbano para morar", ou o trabalho de Johanna Below (2013) sobre reforma agrária.

Ensinando História do Brasil desde 2001, trabalha nesse departamento a brasileira Débora Bendocchi Alves. Obteve seu doutorado pela Universidade de Colônia em 1999, com tese sobre a imagem do Brasil difundida pelo movimento de emigração, na Alemanha, no século XIX (ALVES 2000). Vem estudando emigração alemã para o Brasil, literatura de viagem, relações entre Alemanha e Brasil, a Amazônia. Antes dessa tese, Frank J. Nellissen apresentara, em 1996, estudo também sobre relações brasileiro-alemãs, no passado: a história da empresa mineradora alemã Mannesmann no Brasil; mas trata-se de tese de doutorado não defendida junto ao departamento de História Ibérica e Latino-Americana, mas, sim, na área de Ciências Econômicas (NELLISSEN 1997).

Na década de 1990, o brasilianista Hans-Jürgen Prien ocupou a cátedra de que estamos tratando. Publicara trabalhos sobre o Brasil, em especial sobre história de igrejas e religiosidade. Assim, alguns brasileiros desenvolveram pesquisas sob sua orientação. Além da citada Débora Bendocchi Alves, Sérgio Ricardo da Mata (2002) apresentou tese sobre catolicismo popular em Minas Gerais (séculos XVIII e XIX), e Sérgio Krieger Barreira (2009) analisou o partido político que apoiou o regime militar brasileiro - ARENA -, em tese de 2007.

\footnotetext{
${ }_{5}^{5}$ Tese de Heidemarie Bernstein, defendida na Universidade Técnica de Aachen, cujas indicações bibliográficas estão no artigo anterior (GERTZ 1995).

${ }^{6}$ Wissenschaftliche Mitarbeiter.
} 
Sob orientação da sucessora de Prien, Barbara Potthast, Tim Wätzold (2011) apresentou, em 2010, tese intitulada Do cozinheiro do imperador ao cozinheiro nacional. História da alimentação do império brasileiro: proclamação da 'cozinha brasileira' como parte do processo nacional de criação de uma identidade, no império brasileiro, 1822-1889, entrementes disponível em português (WÄTZOLD 2012). Tendo como uma de suas fontes livros de culinária do Brasil imperial, aborda as tentativas de constituição de uma identidade nacional a partir "da cozinha". Esforços empreendidos para enfrentar as crises políticas e socioeconômicas que assolaram o império brasileiro, na segunda metade do século XIX, são, aqui, iluminados desde uma perspectiva pouco usual.

Outra universidade alemã com longa tradição de estudos sobre história latino-americana é a de Hamburgo. Aquilo que hoje é o Departamento de História Extraeuropeia ${ }^{7}$ se compõe de quatro cátedras, uma delas dedicada à história da América Latina. No período aqui analisado, Horst Pietschmann (até 2005) e Ulrich Mücke (desde 2007) foram responsáveis por ela. Se, afora a coautoria num manual chamado Pequena História do Brasil (com Walter Bernecker e Rüdiger Zoller) (PIETSCHMANN; BERNECKER; ZOLLER 2000), o primeiro não produziu trabalhos dignos de nota sobre nosso país, o segundo o incluiu em estudos do pensamento conservador, mas numa análise conjunta com Península Ibérica e México (MÜCKE 2008). Entre os assistentes, cabe mencionar Jan Kunze, com uma tese a respeito dos movimentos de protesto de 1968 no Brasil e no México (KUNZE 2012).

Como na Universidade de Colônia, também na Universidade de Hamburgo, no decorrer dos últimos 20 anos, foram defendidas teses típicas de história do Brasil, sobre temas diversificados. ${ }^{8}$ Em ordem cronológica, pode-se citar o trabalho de Edgar Helmut Köb, de 2002, sobre a cervejaria Brahma e o comércio de bebidas, nos primeiros 40 anos da República (KÖB 2005). No ano seguinte, veio a pesquisa de Regina Aggio sobre o "cinema novo" brasileiro e o projeto desenvolvimentista dos anos 1950/1960 (AGGIO 2005). Em 2004, foi concluído estudo de história econômica sobre o sistema bancário paulista de 1930 a 1988 (ROSCHMANN 2004). Inserida num amplo debate historiográfico brasileiro, está a tese apresentada em 2006 por Christian Hausser sobre as discussões em torno da evolução da sociedade brasileira nos primeiros três quartos do século XIX; na esteira do conceito de "civilização", o autor procura mostrar que o período não se caracterizou pelo arcaísmo, no confronto com o mundo "civilizado", nem pela tendência simples de copiar o modelo europeu (HAUSSER 2009). Por fim, o brasileiro Fernando Amado Aymoré defendeu, em 2007, tese sobre a ação catequética dos jesuítas no Brasil colonial (AYMORÉ 2009).

Nos protestos estudantis de 1968 na Europa, a América Latina exerceu papel não desprezível. O subcontinente era, então, palco do confronto entre "leste" e "oeste" (mísseis em Cuba, 1962), mas também um lugar do qual se esperavam irrupções revolucionárias (como a revolução cubana, ou a aventura

\footnotetext{
${ }^{7}$ Außereuropäische Geschichte.

${ }^{8}$ No levantamento anterior, foi citada a tese do brasileiro Jorge Luiz da Cunha sobre imigração alemã no Rio Grande do Sul, de 1994 (CUNHA 1995).
} 
de Ernesto Guevara na Bolívia) (PIETSCHMANN 2000, p. 9-10). A criação do Lateinamerika-Institut - LAI, na Universidade Livre de Berlim (FUB), em 1970, provavelmente tenha a ver com essa avaliação (LIEHR 2007, p. 310). Esse "Instituto Central" não faz parte de uma unidade universitária de História, como em Colônia e Hamburgo, sendo multidisciplinar, abrigando desde áreas de estudo sobre populações pré-colombianas, passando por ensino de línguas românicas, para chegar a cátedras de Literatura, Sociologia, Ciência Política, Economia. Mas a História sempre teve sua cátedra específica dentro do LAI.

Porém, também aqui a história do Brasil não se desenvolveu muito, ao menos até o início do século XXI. Em lista apresentada num artigo do então catedrático de História Reinhard Liehr (2007), referente ao período de 1970 a 2005, entre os 46 trabalhos datados de 1995 a 2005, apenas quatro se referem ao Brasil. Um deles, porém, foi produzido por um cientista social brasileiro (sobre democratização recente) e uma economista alemã fez uma análise sobre o "Plano Real". A rigor, apenas um - efetivamente produzido no LAI - pode ser classificado como estudo de História, sobre o discurso em torno da guerra de Canudos. ${ }^{9}$

Nos últimos dez 10 anos, esse quadro, no entanto, sofreu mudanças. Das 18 teses defendidas no LAI de 2010 a 2014, cinco se dedicaram ao Chile, quatro à Argentina, três à América Central. ${ }^{10} \mathrm{O}$ Brasil conseguiu empatar com o México - com duas teses sobre a história de cada um. Em 2012, Christina Peters analisou o futebol na formação da identidade brasileira, nos primeiros 19840 anos da República (PETERS 2012), e Frederik Schulze, em 2014, investigou os discursos colonialistas alemães, tendo como referência a colonização com alemães no sul do Brasil (SCHULZE 2014). ${ }^{11}$

E dentre os 24 doutorandos matriculados no segundo semestre de 2014, quatro se concentram na história do Brasil, orientados pelo catedrático de História Latino-Americana do LAI, Stefan Rinke, e uma quinta faz uma comparação entre Brasil e Argentina. É um avanço, ainda que o tradicional "campeão" de interesse por parte dos historiadores alemães, o México, também esteja contemplado com cinco projetos, e ao Chile estejam dedicados quatro. ${ }^{12}$

A situação reflete um esforço para incrementar estudos sobre o Brasil. Nesse sentido, foi criado, em 2010, o "Forschungszentrum Brasilien", o Centro

\footnotetext{
${ }_{9}^{9} \mathrm{Na}$ ordem em que foram citados, trata-se dos seguintes autores/livros: COSTA 1997; FRITZ 2002; BARTELT 2003; este último também publicado no Brasil (BARTELT 2009). O livro de Assunção (2005) saiu 12 anos após ter deixado o LAI.

${ }^{10}$ Disponível em: http://www.lai.fu-berlin.de/disziplinen/geschichte/promotion_und_postdoc/abgeschlossene_ promotionen/index.html. Acesso em: 27 dez. 2014.

${ }_{11}$ Schulze defendera, antes, dissertação de mestrado sobre "protestantismo e germanidade" no sul do Brasil (SCHULZE 2006).

12 Naquilo que tange ao Brasil, os doutorandos e projetos são: Georg Fischer "'Eisenberge' und Experten: eine globale Wissensgeschichte der Erzvorkommen in Brasilien, 1876-1914"; Kevin Niebauer "Wie die grüne Hölle zum Regenwald wurde: Amazonien als Topos internationaler Umweltorganisationen, 1960-1985"; Igor Gak [brasileiro] "Nazi 'soft power'. Análise sobre a dimensão cultural da política externa alemã para o Brasil (19331942)"; Eduardo Relly [brasileiro] "German immigration and the destruction of the Urwald in Southern Brazil: effects of forest (de)regulation property rights on the devastation (19th century)". O projeto sobre Argentina/ Brasil é de Leonie Herbers "Luftfahrtpioniere: die Anfänge der Luftfahrt in Lateinamerika als transnationales Phänomen - Argentinien und Brasilien im Vergleich, 1898-1930". Disponível em: http://www.lai.fu-berlin.de/ brasil/forschung/dissertationen/index.html e http://www.lai.fu-berlin.de/disziplinen/geschichte/promotion_ und_postdoc/promotionsprojekte/index.html. Acesso em: 20 jan. 2015.
} 
de Estudos Brasileiros, multidisciplinar, no qual alguns outros doutorandos desenvolvem teses sobre aspectos históricos do Brasil, sem que sejam orientados por professores da área de História. ${ }^{13}$ Além disso, cabe citar a instalação, em 2012, da "Gastdozentur Sérgio Buarque de Holanda", uma "docência de visitante". Desde 2013, é catedrática-júnior a brasilianista Debora Gerstenberger, atualmente pesquisando sobre tecnologia e ditadura militar. Conclui-se, portanto, que a dedicação a temas da história do Brasil no LAI, no momento, está num crescendo.

Sem dúvida, nas universidades de Colônia, Hamburgo e na Livre de Berlim estão os principais centros de estudos sobre América Latina. Mas outras universidades alemãs também registram tradições para a área. Uma delas é a de Erlangen-Nürnberg, onde, na década de 1980, brasileiros e alemães desenvolveram teses sobre história brasileira. ${ }^{14}$ Ali existe, atualmente, uma cátedra sobre "Ciência dedicada ao Exterior (Culturas de Línguas Românicas)", ${ }^{15}$ que de 1992 a 2014 foi ocupada por Walther Bernecker. Apesar de ele dedicar-se à história espanhola, portuguesa e latino-americana dos séculos XIX e XX, e apesar de ter publicado, com Horst Pietschmann e Rüdiger Zoller, o citado manual Uma pequena história do Brasil, as listas de suas publicações registram quase nada de específico sobre história brasileira. Rüdiger Zoller - abstraindo do manual - só dedicou textos menores à história do Brasil (ZOLLER 2009). Ultimamente, apenas um dos colaboradores, Sören Brinkmann, estudou a história da política estatal em relação à alimentação no Brasil, durante os primeiros 50 anos da República, em recente tese de livre-docência (BRINKMANN 2014b). ${ }^{16}$ Antes desse estudo, o autor publicara textos menores sobre o tema (BRINKMANN 2013; 2014a).

Outro centro que merece referência é a jovem Universidade Católica de Eichstätt (fundada em 1980), que mantém uma cátedra de História da América Latina. Ela é ocupada, atualmente, por Thomas Fischer, em cujo currículo se encontra apenas um capítulo sobre o Brasil e a Liga das Nações (FISCHER 2013). ${ }^{17}$ O administrador do Instituto Central de Estudos sobre a América Latina, KarlDieter Hoffmann, com formação em Ciência Política, relaciona uma publicação sobre a história do modelo de desenvolvimento brasileiro (HOFFMANN 1995), mas depois disso parece não ter-se interessado mais pelo Brasil. O colaborador científico ${ }^{18}$ da cátedra, o colombiano Andrés Jiménez Ángel, também não registra estudos sobre a história do Brasil em seu currículo.

\footnotetext{
${ }_{13}$ Alguns exemplos: Jens Weigelt Reforming development trajectories? Institutional change in forest tenure in the Brazilian Amazon (tese 2011); Maria Backhouse Grüne Landnahme. Fallstudie zur Expansion der Palmölproduktion in Amazonien (Pará/Brasilien) (tese 2014); Airton Adelar Mueller "Lokales Regieren, Sozialkapital und Entwicklung im Süden von Brasilien" (projeto de tese em andamento, em 2014); Philipp Temme "Die Entwicklung der Bond-Märkte in Brasilien und Mexiko" (projeto de tese em andamento, em 2014). Disponível em: http://www.lai.fuberlin.de/brasil/forschung/dissertationen/index.html. Acesso em: 27 dez. 2014.

${ }_{14}$ No arrolamento anterior, constavam as teses de Luiz do Nascimento [1983], Wolfgang Penkwitt [1983], Maria da Guia Santos [1984], Ana Maria Barros dos Santos [1985]. As indicações bibliográficas estão no artigo (GERTZ 1995).

${ }_{15}$ Auslandswissenschaft (Romanischsprachige Kulturen).

16 Denomina-se, aqui, "tese de livre-docência" aquilo que no sistema acadêmico alemão é chamado Habilitationsschrift, tipo de tese de pós-doutorado que habilita a assumir uma cátedra.

17 Essa cátedra foi ocupada até 2006 por Hans-Joachim König, que publicou recentemente uma interessante História do Brasil (KÖNIG 2014).

18 Wissenschaftlicher Mitarbeiter.
} 
Essa tendência se reflete nos temas das 17 teses em andamento: a Colômbia está contemplada em quatro projetos, três se referem à Argentina, dois ao Peru, dois a temas gerais sobre a região. Ao lado de América Central, Chile, México (mais Alemanha e Espanha), o Brasil aparece em um único projeto - de uma doutoranda brasileira. ${ }^{19}$ Uma exceção nesse quadro de aparente interesse restrito pela história do Brasil é a tese de livre-docência de Sven Schuster, de 2012. Schuster fez seu mestrado, seu doutorado e sua livre-docência em Eichstätt. Nesta última, analisou, a partir das grandes exposições nacionais brasileiras e da presença brasileira em exposições internacionais, os elementos "raça", "progresso" e "civilização", vistos como fundamentais para a constituição da nação. Metodologicamente, além da análise de "discursos" escritos, o autor recorreu a "discursos" imagéticos (SCHUSTER 2012).

Na Universidade de Erfurt, existia uma cátedra de História Latino-Americana e do Sudoeste Europeu ${ }^{20}$, ocupada por Peer Schmidt, desde 1999, e que foi extinta após sua morte, em 2009. O próprio Schmidt não fez estudos significativos sobre o Brasil, mas ao menos um de seus alunos, Sebastian Dorsch, mesmo tendo defendido, em 2008, tese sobre a história mexicana, publicou trabalhos sobre história brasileira (DORSCH 2007; 2013; 2014), e desde 2010 desenvolve projeto sob o título Kulturelle Zeiträume einer atlantischen Metropole: São Paulo 1867-1930 (Espaços temporais culturais de uma metrópole atlântica: São Paulo 1867-1930). ${ }^{21}$

$\mathrm{Na}$ Universidade de Bielefeld, um dos mais destacados centros da 200 autointitulada Ciência Social Histórica alemã, existe um departamento de História Ibérica e Latino-Americana, ${ }^{22}$ mas registra pouca produção sobre o Brasil. Dos três pequenos textos de pessoas ligadas ao departamento, um não é "histórico", e sim "sociológico", essencialmente teórico, com referência ao Brasil no título, e nada mais (THIES; KALTMEIER 2008); um segundo tende para a Ciência Política, não para a História, pois, apesar de iniciar com uma análise comparativa entre Argentina e Brasil a respeito da ação social do Estado nos anos 1930, centra sua atenção nas tendências liberais das duas últimas décadas do século $X X$, e nas mudanças mais recentes (TITTOR; LEUTBOLD 2008); o texto mais antigo compara possibilidades de ascensão social de escravos libertos em Recife e em Havana, na segunda metade do século XIX (KEMMER 2005).

Na Universidade de Münster, existe uma cátedra de "História Extraeuropeia", 23 mas a titular, Silke Hensel, tem publicado estudos sobre o México, e das demais pessoas do grupo ninguém apresenta publicações relevantes sobre o Brasil. Exceção é o referido Frederik Schulze, que passou a ser colaborador científico em $2014,{ }^{24}$ cuja formação se deu no LAI da Universidade Livre de Berlim, e que efetivamente produziu trabalhos sobre o Brasil.

\footnotetext{
${ }_{19}$ Disponível em: http://www.ku.de/ggf/geschichte/geschlateinam/forschung/habilitationen-unddissertationen/. Acesso em: 30 dez. 2014.

${ }^{20}$ Lateinamerikanische und Südwesteuropäische Geschichte.

21 Disponível em: https://www.uni-erfurt.de/en/geschichte/dfgsaopaulo/faculty-and-staff/dr-sebastiandorsch/ausfuehrlicher-lebenslauf/. Acesso em: 1 jan. 2015.

${ }^{22}$ Iberische und Lateinamerikanische Geschichte.

${ }^{23}$ Außereuropäische Geschichte.

${ }^{24}$ Wissenschaftlicher Mitarbeiter.
} 
Na Universidade de Leipzig, há um departamento de História Comparada, no qual pesquisadores se dedicam à História Ibero-Americana, mas nas publicações não se detecta interesse pelo Brasil, com uma exceção: em 2011 foi defendida a tese de Debora Gerstenberger, com o título "Transfer et impera": die Verlegung des portugiesischen Königshofes nach Brasilien: Polizei, Regierung in Zeiten der globalen Krise (1807-1821), sobre "a transferência da corte portuguesa para o Brasil: polícia, governo em tempos de crise global" (GERSTENBERGER 2013).

Além da de Leipzig, a Universidade de Rostock também se localiza no território que constituía a República Democrática Alemã, e era relativamente conhecida por estudos sobre a América Latina, incluindo a História, tendo sido feitas ali pesquisas sobre história brasileira (AHRENDT-VÖLSCHOW 2004; ALVES 2006, p. 162-163). Depois da "queda do muro", ocorreram, porém, mudanças, e atualmente a preocupação com o subcontinente americano se restringe a um grupo de trabalho sobre política contemporânea.

Na Universidade de Bremen, há um grupo de trabalho sobre história da América Latina, mas as listas de publicações dos participantes mostra que não há nada de significativo que seja específico do Brasil. Da mesma forma, a cátedra de História da América Latina e do Caribe na Universidade de Hannover tem como foco a América Central. Entre as publicações dos participantes, apenas Ulrike Schmieder arrola sua tese de livre-docência - de 2002, na Universidade de Colônia -, sobre gênero e etnicidade a partir de relatos de viagem sobre México, Brasil e Cuba, nos séculos XVIII e XIX (SCHMIEDER 2004), e um artigo sobre a escravização de africanos no Brasil (SCHMIEDER 2003b). ${ }^{25}$ Além disso, Mario Peters está trabalhando numa tese sobre Segregação socioespacial e a influência de imaginações estereotípicas sobre políticas habitacionais urbanas no Brasil de aproximadamente 1920 a 1970.26

Esse arrolamento de estudos da história brasileira na Alemanha pode abrigar injustiças, pois é possível que pesquisadores não inseridos em departamentos que se dedicam expressamente à América Latina estejam produzindo trabalhos relevantes, aqui não detectados. Há exemplos nesse sentido. Na Universidade de Munique, por exemplo, existe, desde 1949, um Amerika-Institut, que se dedica à América do Norte. Ali, a austríaca Ursula Prutsch leciona história cultural americana. 27 Ela se formou na Áustria, onde, em 1993, produziu uma tese sobre emigração austríaca para o Brasil (PRUTSCH 1996). E, desde então, publicou trabalhos sobre outros temas da história brasileira, entre eles uma história cultural (PRUTSCH 2013). Da mesma forma, trabalha no extremo-sul alemão - na Universidade de Constança - Nina Schneider, que se doutorou na Inglaterra, sob orientação de Matthias Röhrig Assunção - doutorado na Alemanha -, de cujas publicações seja aqui citada apenas a mais recente (SCHNEIDER 2014).

\footnotetext{
${ }^{25}$ Disponível em: http://www.hist.uni-hannover.de/geschichte_lateinamerikas_hist.html. Acesso em: 4 jan. 2015.

${ }^{26}$ Disponível em: http://www.hsozkult.de/hfn/conferencereport/id/tagungsberichte-4057. Acesso em: 23 dez. 2014.

27 Disponível em: http://www.amerikanistik.uni-muenchen.de/personen/privatdozenten/prutsch/lebenslauf/ index.html. Acesso em: 3 jan. 2015.
} 
Esses casos ilustram a possibilidade de que haja outros pesquisadores estudando aspectos de nossa história, no grande universo representado pelas universidades alemãs. ${ }^{28}$

\section{Tentativa para definir tendências}

Nas referências bibliográficas que seguem há, no mínimo, 36 teses (doutorado e livre-docência) que se referem à história do Brasil. ${ }^{29}$ Parte-se do pressuposto de que refletem dedicação profunda a um tema, e, portanto, constituem amostra representativa de pesquisas substanciais. Por falta de espaço, não é possível analisá-las de forma crítica, assim que se fará aqui uma simples tentativa de agrupá-las, com base no período histórico a que se dedicam. ${ }^{30}$ Depois, se tentará verificar se é possível descobrir alguma "tendência" temática. ${ }^{31}$

Ao período colonial, foram dedicadas apenas três teses, todas sobre assuntos religiosos (AYMORÉ 2010; JAECKEL 2007; MATA 2002). O império está tematizado em seis, com preferência nítida por algum aspecto sobre a construção de uma identidade nacional. Christian Hausser (2009) analisou as discussões em torno do conceito de "civilização" para a configuração da nação brasileira. Sven Schuster (2012) utilizou materiais sobre exposições internacionais e nacionais para aferir a imagem que se pretendeu difundir a respeito do Brasil. Tim Wätzold (2011) recorreu à culinária imperial para mostrar sua instrumentalização na tentativa de definir a identidade nacional brasileira. E Georg Wink (2009) rastreou narrativas que, ao longo do tempo, procuraram definir uma "ideia" de Brasil.32

Apesar de aparentemente sem relação com "identidade", a tese de Margrit Prussant (2008) se aproxima desse tema, pois, a partir de fotografias com vestígios da escravidão, localiza identidades tanto da população atingida quanto das elites brancas. Debora Gerstenberger (2013b) estudou efeitos da vinda da família real portuguesa para o Brasil, em 1808, sobre o desenvolvimento do país.

Além do fato de os dados apresentados por Prussant, Schuster e Wink "ultrapassarem" o período monárquico, há ao menos uma tese referente à República que também aborda a "identidade" - é a de Christina Peters (2012), que procura mostrar como o futebol foi instrumentalizado, nos primeiros 40 anos, para a construção de identidades. Mas, nas 13 teses que tematizam outros aspectos da história republicana, é mais difícil estabelecer alguma "tendência". Quatro se dedicam à história econômica - duas delas a tradicionais empresas industriais (NELLISSEN 1997; KÖB 2005), uma à história de bancos paulistas (ROSCHMANN 2004) e outra ao "Plano Real" (FRITZ 2002).

\footnotetext{
${ }^{28}$ Isso sem referir o fato de que há instituições não universitárias cuja produção deveria ser avaliada, como a do Instituto Ibero-Americano de Berlim.

${ }^{29}$ Apesar da tendência a um crescendo na dedicação ao Brasil no LAI/FUB, os números sobre o conjunto da produção alemã de teses apontam em direção menos otimista - na primeira metade dos 20 anos abrangidos por este levantamento foram produzidas 20, na segunda apenas 15.

${ }_{30}$ Quando um trabalho perpassa mais de um período, foi classificado pelo primeiro período abrangido.

${ }^{31}$ Pela brevidade da referência, o leitor não deve imaginar que o número de palavras ou frases dedicadas a determinado trabalho reflete a importância que Ihe é atribuída.

32 Neste último caso, a análise inicia com o Brasil colonial, e vai até a República. O trabalho foi classificado para o período imperial porque a "ideia" de nação brasileira, efetivamente, adquire sentido nesse período.
} 
Entre as oito restantes, há significativa diversidade, indo desde política partidária (BARREIRA 2009), protestos (KUNZE 2012), passando por políticas administrativas sobre alimentação (BRINKMANN 2014b). Mas cinco das teses que se dedicam ao período republicano podem ser classificadas sob um viés cultural(ista) - incluem "cinema novo" (AGGIO 2005), "discursos sobre Canudos" (BARTELT 2003; 2009), arquitetura moderna (LEHMANN 2004), teorias pedagógicas (RIGGENMANN 2006), música de Villa-Lobos (ZACHER 2005).

Mas não há dúvida de que - ignorando a classificação cronológica - o binômio Brasil versus Alemanha é abordado em treze das teses (quatorze, se incluirmos a de Nellissen sobre a siderúrgica Mannesmann ${ }^{33}$ ), fato que representa mais de um terço. Oliveira (2005) aborda o tema ainda pouco explorado das relações entre os dois países imediatamente após a Segunda Guerra Mundial. A emigração de alemães para o Brasil e seus desdobramentos estão - sob variados ângulos - nos trabalhos de Alves (2000), Diel (2001), Doll (2002), Goldenbaum (2012), Neumann (2005), Schulze (2014b), Wolf (2010). Os efeitos do nazismo estão presentes nos estudos de Gaudig e Veit (1997), Isolan (2010), Moraes (2005), Müller (1997), Stanley (1996).

Resumindo em três frases a contribuição que este artigo pretendeu trazer, pode-se dizer que o brasilianismo nos estudos históricos na Alemanha não recebeu a mesma atenção que a história de alguns outros países latino-americanos. Mas, mesmo assim, há alguns trabalhos que merecem atenção não só daqueles que dominam a língua alemã, pois alguns estão publicados em português. E a lista bibliográfica que segue pretende dar uma ideia da produção dos últimos 20 anos.

Uma tarefa para o futuro consiste em tentar avaliar se essa produção teve algum efeito sobre a escrita e a compreensão da história brasileira, seja dentro do Brasil, seja alhures. Além disso, representa desafio maior uma explicação para a tendência de uma maior atenção a outros países latino-americanos, em detrimento do Brasil, apesar de seu "tamanho e importância" - como escreveram dois analistas alemães, aqui citados. Por enquanto, só se pode levantar algumas hipóteses de caráter puramente especulativo: há uma maior tendência de domínio da língua espanhola que da portuguesa entre o público acadêmico alemão; a historiografia brasileira apresenta longa tradição de alinhamento com a historiografia francesa, fato do qual decorrem contatos mais escassos com historiadores alemães; tanto universidades quanto agências de fomento de alguns países hispano-americanos apresentam uma maior abertura para a tradição historiográfica alemã; nas demandas mais antigas e tradicionais de pesquisa histórica vindas do Brasil em relação à Alemanha estava muito presente o interesse pela e(i)migração, tema que, muitas vezes, esteve contaminado pela ideologia do "germanismo", e que não é mais bem-vinda - eu próprio fui "vítima" de uma situação dessas: alguns anos atrás, um colega alemão me convidou para um evento sobre Lutero, pedindo que falasse sobre os luteranos

33 Convém lembrar que a citada tese de Köb (2005) não se enquadra aqui, porque o fundador da Brahma era suíço (não alemão). 
no Brasil; perguntou se eu estaria disposto a apresentar meu trabalho em um ou dois outros centros universitários de história latino-americana, com que poderia aliviar os gastos de seu evento; concordei, mas algum tempo depois me comunicou, muito constrangido, que a resposta que recebeu foi que se eu pudesse falar sobre um tema "brasileiro" teriam interesse em me ouvir, mas os luteranos no Brasil não eram exatamente um tema brasileiro. Repito: estas são conjecturas puramente especulativas, que, obviamente, precisariam ser aprofundadas para adquirir consistência.

\section{Referências bibliográficas}

AGGIO, Regina. Cinema Novo - ein kulturpolitisches Projekt in Brasilien: Ursprünge des neuen brasilianischen Films im Kontext der Entwicklungspolitik zwischen 1956 und 1964. Remscheid: Gardez!-Verlag, 2005.

AHRENDT-VÖLSCHOW, Dörte. Die Lateinamerikawissenschaften an der Universität Rostock von 1958 bis 1995. Rostock: Universidade de Rostock, 2004.

ALVES, Débora Bendocchi. Das Brasilienbild der deutschen Auswanderungsbewegung im 19. Jahrhundert. Berlin: Wissenschaftlicher Verlag, 2000.

204 - Jürgen Hell e a produção historiográfica sobre o Brasil na ex-República Democrática Alemã. Locus, v. 12, n. 1, p. 161-179, 2006.

ASMUS, Sylvia; ECKL, Marlen (eds.). „... mehr vorwärts als rückwärts schauen..." /"... olhando mais para frente do que para trás...": das deutschsprachige Exil in Brasilien 1933-1945/o exílio de língua alemã no Brasil 1933-1945. Berlin: Hentrich \& Hentrich, 2013.

ASSUNÇÃO, Mathias Röhrig. Capoeira. The history of an Afro-Brazilian martial art. London: Routledge, 2005.

AYMORÉ, Fernando Amado. Die Jesuiten im kolonialen Brasilien: Katechese als Kulturpolitik und Gesellschaftsphänomen (1549-1760). Frankfurt: Peter Lang, 2009.

BADER, Wolfgang (ed.). Deutsch-brasilianische Kulturbeziehungen: bestandaufnahme, herausforderungen, perspektiven. Frankfurt: Vervuert, 2010.

BARREIRA, Sérgio Krieger. Die ARENA: zivile Regierungspartei unter Bedingungen der Militärherrschaft in Brasilien. Mettingen: BrasilienkundeVerlag, 2009.

BARTELT, Dawid Danilo. Nation gegen Hinterland: der Krieg von Canudos in Brasilien: ein diskursives Ereignis. Stuttgart: Franz Steiner, 2003.

Sertão, república, nação. São Paulo: EDUSP, 2009. 
BELOW, Johanna. Zwischen Anspruch und Wirklichkeit: dieGleichberechtigung von Frauen im brasilianischen Agrarreformprozess. Köln: Kompetenznetz Lateinamerika, 2013.

BRINKMANN, Sören. Ernährungspolitik im Estado Novo: die "Milchrevolution" von Rio de Janeiro. In: FISCHER, Georg; PETERS, Christina; RINKE, Stefan; SCHULZE, Frederik (eds.). Brasilien in der Welt: Region, Nation und Globalisierung 1870-1945. Frankfurt: Campus, 2013, p. 271-295.

BRINKMANN, Sören. Leite e modernidade: ideologia e políticas de alimentação na era Vargas. História, Ciências, Saúde - Manguinhos, v. 21, n. 1, p. 263-280, 2014a.

BRINKMANN, Sören. Kampf den Volksvergiftern! Lebensmittelkontrolle und Lebensmittelpolitik in Brasilien, 1890-1945. Tese (Livre-Docência em História). Zentralinstitut für Lateinamerikastudien, Universidade Católica de Eichstätt, Eichstätt, 2014b.

COSTA, Sérgio. Dimensionen der Demokratisierung. Öffentlichkeit, Zivilgesellschaft und lokale Partizipation in Brasilien. Frankfurt: Vervuert, 1997.

CUNHA, Jorge Luiz da. Rio Grande do Sul und die deutsche Kolonisation. Santa Cruz do Sul: Gráfica Léo Quatke da UNISC, 1995.

DOLL, Johannes. Geschichtstexte verstehen in einer anderen Sprache: eine vergleichende Untersuchung der Leseleistung von Schülern aus deutsch-brasilianischen Begegnungsschulen und deutschen Gymnasien. Frankfurt: Peter Lang, 2002.

DIEL, Paulo Fernando. „Ein katholisches Volk, aber eine Herde ohne Hirte”: der Anteil deutscher Orden und Kongregationen an der Bewahrung deutscher Kultur und an der Erneuerung der katholischen Kirche in SüdBrasilien (1824-1935/38). Remscheid: Gardez!-Verlag, 2001.

DORSCH, Sebastian. Die Yankee City São Paulo im verzeitlichten Atlantik: die Nerven- und Modernekrankheit Neurasthenie. In: FISCHER, Georg; PETERS, Christina; RINKE, Stefan; SCHULZE, Frederik (eds.). Brasilien in der Welt: Region, Nation und Globalisierung 1870-1945. Frankfurt: Campus, 2013, p. 296-319.

. Os paulistanos, "ianques do sul", e a "doença moderna", a neurastenia, nas primeiras décadas do século $X X$. História, Ciências, Saúde Manguinhos, v. 21, n. 1, p. 169-180, 2014.

; WAGNER, Michael. Gezähmter Dschungel - industrialisierte Agrarwirtschaft - romantisierter Landloser. Die Mystifizierung des Ländlichen in der deagrarisierten Gesellschaft Brasilien. Geschichte und Gesellschaft, ano 33, n. 4, p. 546-574, 2007.

ECKL, Marlen; HARLES, Berhard (eds.). „... auf brasilianischem Boden fand ich eine neue Heimat". Autobiographische Texte deutscher Flüchtlinge des Nationalsozialismus. Remscheid: Gardez!-Verlag, 2005. 
. „Das Paradies ist überall verloren": das Brasilienbild von Flüchtlingen des Nationalsozialismus. Frankfurt: Vervuert, 2010.

FISCHER, Georg. Imigrantes de língua alemã e as visões do paraíso da elite capixaba, 1847-1862. Espaço Plural, v. 9, n. 19, p. 59-66, 2008.

; PETERS, Christina; SCHULZE, Frederik. Brasilien in der Globalgeschichte.

In: FISCHER, Georg; PETERS, Christina; RINKE, Stefan; SCHULZE, Frederik (eds.). Brasilien in der Welt: Region, Nation und Globalisierung 1870-1945. Frankfurt: Campus, 2013, p. 9-50.

; ; RINKE, Stefan; SCHULZE, Frederik (eds.). Brasilien in der

Welt: Region, Nation und Globalisierung 1870-1945. Frankfurt: Campus, 2013.

- Minério de ferro, geologia econômica e redes de experts entre Wisconsin e Minas Gerais, 1881-1914. História, Ciências, Saúde - Manguinhos, v. 21 , n. 1, p. 247-262, 2014.

- Das Staatsunternehmen als Expertenarena. Die Anfangsjahre der Companhia Vale do Rio Doce, 1942-1951. In: REUFELS, Delia González de; RINKE, Stefan (eds.). Expert Knowledge in Latin American History. Local, Transnational and Global Perspectives. Stuttgart: Heinz, 2014, p. 109-138.

FISCHER, Thomas. Brasilien und der Völkerbund. In: RAASCH, Markus; HIRSCHMÜLLER, Tobias (eds.). Von Freiheit, Solidarität und Subsidiarität - Staat und Gesellschaft der Moderne in Theorie und Praxis. Berlin: Duncker \& Humblot 2013, p. 245-279.

FLESSEL, Sina. Die Nikkei in Brasilien. Identität und Wandel. In: FISCHER, Thomas; GOSSEL, Daniel (eds.). Migration in internationaler Perspektive. München: Allitera, 2009, p. 274-301.

FRITZ, Barbara. Entwicklung durch wechselkurs-basierte Stabilisierung? Der Fall Brasilien. Marburg: Metropolis, 2002.

GAUDIG, Olaf; VEIT, Peter. Der Widerschein des Nazismus: das Bild des Nationalsozialismus in der deutschsprachigen Presse Argentiniens, Brasiliens und Chiles 1932-1945. Berlin: Wissenschaftlicher Verlag, 1997. ; Hakenkreuz über Südamerika: Ideologie, Politik, Militär. Berlin: Wissenschaftlicher Verlag, 2004.

GERSTENBERGER, Debora. Gilberto de Mello Freyre (1900-1987). In: MIDDELL, Mathias; ENGEL, Ulf (eds.). Theoretiker der Globalisierung. Leipzig: Leipziger Universitätsverlag, 2010, p. 225-239.

. Gilberto Freyre: Nationalhistoriker oder Vordenker der Globalgeschichte? In: FISCHER, Georg; PETERS, Christina; RINKE, Stefan; SCHULZE, Frederik (eds.). Brasilien in der Welt: Region, Nation und Globalisierung 1870-1945. Frankfurt: Campus, 2013a, p. 51-70. 
. Gouvernementalität im Zeichen der globalen Krise: der Transfer des portugiesischen Königshofes nach Brasilien. Köln: Böhlau, 2013b.

. Gilberto Freyre: um teórico da globalização? História, Ciências, Saúde

- Manguinhos, v. 21, n. 1, p. 111-120, 2014.

GERTZ, René E. A História do Brasil na Alemanha (1980-1994). Anos 90, v. 3, n. 4, p. 87-113, 1995.

GÖBEL, Barbara; BIRLE, Peter. Investigación sobre América Latina en Alemania en el ambito de las Ciencias Económicas, las Ciencias Sociales y las Humanidades. Berlin: Ibero-Amerikanisches Institut, 2012.

GOLDENBAUM, Jean. „Neue Noten unter einem neuem Himmel”: die in Brasilien eingewanderten deutschsprachigen Komponisten und deren Einfluss auf die brasilianische Musik. Tese (Doutorado em História). Philosophisch-Sozialwissenschaftliche Fakultät, Universidade de Augsburg, Augsburg, 2012.

HAUSSER, Christian. Auf dem Weg der Zivilisation: Geschichte und Konzepte gesellschaftlicher Entwicklung in Brasilien (1808-1871). Stuttgart: Franz Steiner, 2009.

HOFFMANN, Karl-Dieter. Ökonomischer Fortschritt und soziale Marginalisierung: die historische Genese des brasilianischen Wachstumsund Entwicklungsmodels. Eine Skizze. Ausgsburg: ISLA, 1995.

ISOLAN, Flaviano Bugatti. Filmabsatzgebiet Brasilien: die Rezeption des deutschen Films in Brasilien in den 1920er und 30er Jahren. Tese (Doutorado em História). Zentrum für Antissemitismusforschung, Universidade Técnica de Berlim, Berlin, 2010.

JAECKEL, Volker. Von Alterität, Anthropophagie und Missionierung: der Einfluss der Jesuiten auf die kulturelle Identität Brasiliens in der Kolonialzeit (1549-1711). Stuttgart: Ibidem, 2007.

KEMMER, Jochen. „Farbige Aussteiger” in der Sklavereigesellschaft - Recife und Santiago de Cuba (1850-1888). In: NITSCHACK, Horst (ed.). Brasilien im amerikanischen Kontext. Vom Kaiserreich zur Republik: Kultur, Gesellschaft, Politik. Frankfurt: TFM, 2005, p. 117-149.

KÖB, Edgar Helmut. Die Brahma-Brauerei und die Modernisierung des Getränkehandels in Rio de Janeiro 1888 bis 1930. Stuttgart: Franz Steiner, 2005.

KÖNIG, Hans-Joachim. Geschichte Brasiliens. Stuttgart: Reclam, 2014.

KUNZE, Jan. Die Protestbewegungen von 1968 in Mexiko und Brasilien: zwischen lokalem Protest und globaler Revolte. Tese (Doutorado em História). Lateinamerika-Studien, Universidade de Hamburgo, Hamburg, 2012.

LEHMANN, Steffen. Der Weg Brasiliens in die Moderne: eine Bewertung und 
Einordnung der modernen Architektur Brasiliens (1930-1955). Münster: LIT, 2004.

LIEHR, Reinhard. Lateinamerika-Forschung am Lateinamerika-Institut der Freien Universität Berlin, 1979-2005. Jahrbuch für Geschichte Lateinamerikas, n. 44, p. 309-325, 2007.

LIENHARD, Martin. Der Diskurs aufständischer Sklaven in Brasilien 1798-1938: Versuch einer "archäologischen" Annäherung. Comparativ - Zeitschrift für Globalgeschichte und Vergleichende Gesellschaftsforschung, n. 2, p. 44-67, 2003.

LORENZ, Stella. Processo de purificação: expectativas ligadas à imigração alemã para o Brasil (1880-1918). Espaço Plural, v. 9, n. 19, p. 29-37, 2008.

Das Eigene und das Fremde: Zirkulationen und Verflechtungen zwischen eugenischen Vorstellungen in Brasilien und Deutschland zu Beginn des 20. Jahrhunderts. Berlin: desiguALdades, 2001.

MAINKA, Peter Johann. Roland und Rolândia im Nordosten von Paraná: Gründugs- und Frühgeschichte einer deutschen Kolonie in Brasilien (1932-1944/45). São Paulo: Cultura Acadêmica/Instituto MartiusStaden, 2008.

- O início da colonização do Brasil no contexto da expansão marítima portuguesa (1415-1549). In: TOLEDO, Cézar de Alencar de; RIBAS, Maria

208 Aparecida de Araújo Barreto; SKALINSKI Júnior, Oriomar (orgs.). Origens da educação escolar no Brasil colonial (I). Maringá: Editora da UEM, 2012, p. 17-88.

MATA, Sérgio Ricardo da. Catolicismo popular, espaço e protourbanização em Minas Gerais, Brasil: séculos XVIII-XIX. Tese (Doutorado em História). Zentrum Lateinamerika, Universidade de Colônia, Köln, 2002.

MORAES, Luís Edmundo de Souza. Konflikt und Anerkennung: die Ortsgruppe der NSDAP in Blumenau und Rio de Janeiro: Berlin: Metropol, 2005.

MÜCKE, Ulrich. Gegen Aufklärung und Revolution. Die Entstehung konservativen Denkens in der iberischen Welt. Spanien, Portugal, Mexiko und Brasilien, 1770-1840. Köln: Böhlau, 2008.

MÜLLER, Jürgen. Nationalsozialismus in Lateinamerika. Die Auslandsorganisation der NSDAP in Argentinien, Brasilien, Chile und Mexiko, 1931-1945. Stuttgart: Akademischer Verlag, 1997.

NELLISSEN, Frank J. Das Mannesmann-Engagement in Brasilien von 1892 bis 1995: Evolutionspfade internationaler Unternehmertätigkeit aus wirtschaftshistorischer Sicht. München: C. H. Beck, 1997.

NEUMANN, Gerson Roberto. „Brasilien ist nicht weit von hier": die Thematik der deutschen Auswanderung nach Brasilien in der deutschen Literatur im 19. Jahrhundert (1800-1870). Frankfurt: Peter Lang, 2005. 
NITSCHACK, Horst (ed.). Brasilien im amerikanischen Kontext. Vom Kaiserreich zur Republik: Kultur, Gesellschaft, Politik. Frankfurt: TFM, 2005.

OLIVEIRA, Ione. Aussenpolitik und Wirtschaftsinteresse: in den Beziehungen zwischen Brasilien und der Bundesrepublik Deutschland 1949-1966. Frankfurt: Peter Lang, 2005.

PETERS, Christina. "O nome do paiz em jogo". Fussball und Identität in Brasilien aus transnationaler Perspektive, 1894-1930. Tese (Doutorado em História). Lateinamerika-Institut, Universidade Livre de Berlim, Berlin, 2012.

Formação de relações regionais em um contexto global: a rivalidade futebolística entre Rio de Janeiro e São Paulo durante a Primeira República. História, Ciências, Saúde - Manguinhos, v. 21, n. 1, p. 151-168, 2014.

PIETSCHMANN, Horst. La historia de América Latina como subdisciplina histórica.

Diálogo Científico: Revista Semestral de Investigaciones Alemanas sobre Sociedad, Derecho y Economia, v. 9, n. 1/2, p. 9-43, 2000.

; BERNECKER, Walther; ZOLLER, Rüdiger. Eine kleine Geschichte Brasiliens. Frankfurt: Suhrkamp, 2000.

PRUSSANT, Margrit. Bilder der Sklaverei: Fotografien der afrikanischen Diaspora in Brasilien 1860-1920. Berlin: Reimer, 2008.

PRUTSCH, Ursula. Das Geschäft mit der Hoffnung: österreichische Auswanderung nach Brasilien, 1918-1938. Wien: Böhlau, 1996.

PRUTSCH, Ursula. El príncipe Rodolfo de Habsburgo posee tierra en el Brasil. Problemas que afronta la historia de la migración austro-hungara. In: OPATRNÝ, Josef (ed.). Emigración centroeuropea a América Latina. Praha: Universidade Carolina, 2001, p. 195-204.

Creating good neighbors? Die Kultur- und Wirtschaftspolitik der USA in Lateinamerika, 1940-1946. Stuttgart: Franz Steiner, 2008, p. 134-332.

. Nelson A. Rockefeller's Office of Inter-American Affairs in Brazil. In: CRAMER, Gisela; PRUTSCH, Ursula (eds.). iAméricas unidas! Nelson A. Rockefeller's Office of Inter-American Affairs (1940-1946. Frankfurt: Vervuert, 2012, p. 249-282.

Brasilien: eine Kulturgeschichte. Bielefeld: Transcript, 2013a.

. Von Indigenen, Europäern und Japanern: die Globalisierung Paranás im frühen 20. Jahrhundert. In: FISCHER, Georg; PETERS, Christina; RINKE, Stefan; SCHULZE, Frederik (eds.). Brasilien in der Welt: Region, Nation und Globalisierung 1870-1945. Frankfurt: Campus, 2013b, p. 139-163.

- Migrantes na periferia: indígenas, europeus e japoneses no Paraná durante as primeiras décadas do século XX. História, Ciências, Saúde Manguinhos, v. 21, n. 1, p. 218-236, 2014. 
RIGGENMANN, Konrad. Escola Nova, escola ativa: John Deweys Pädagogik am Beispiel ihrer Rezeption in Brasilien. Oldenburg: pfv, 2006.

RINKE, Stefan. Auslanddeutsche no Brasil (1918-1933): nova emigração e mudança de identidades. Espaço Plural, v. 9, n. 19, p. 39-48, 2008.

. Deutschland und Brasilien, 1871-1945: Beziehungen zwischen Räumen.

In: FISCHER, Georg; PETERS, Christina; RINKE, Stefan; SCHULZE, Frederik (eds.). Brasilien in der Welt: Region, Nation und Globalisierung 1870-1945. Frankfurt: Campus, 2013, p. 243-270.

; SCHULZE, Frederik. Kleine Geschichte Brasiliens. München: C. H. Beck, 2013.

. Alemanha e Brasil, 1870-1945: uma relação entre espaços. História, Ciências, Saúde - Manguinhos, v. 21, n. 1, p. 299-316, 2014.

ROSCHMANN, Michael. Die Entwicklung des Bankenzentrums São Paulos in den Jahren von 1930 bis 1988. Hamburg: Tectum-Verlag, 2004.

SCHMIEDER, Ulrike. Die Sklaverei von Afrikanern in Brasilien. Comparativ Zeitschrift für Globalgeschichte und Vergleichende Gesellschaftsforschung, n. 2, p. 26-43, 2003.

Geschlecht und Ethnizität in Lateinamerika im Spiegel von Reiseberichten: Mexiko, Brasilien und Kuba (1780-1880). Stuttgart: Akademischer Verlag, 2004.

SCHNEIDER, Nina. Brazilian Propaganda: legitimizing an authoritarian regime. Gainesville: University Press of Florida, 2014.

SCHÖNARDIE, Paulo Alfredo. Bäuerliche Landwirtschaft im Süden Brasiliens: historische, theoretische und empirische Studie zu Ernährungssouveränität, Modernisierung, Wiederbelebung und Staatsfunktion. München: Oekom, 2013.

SCHULZE, Frederik. Protestantismus und Deutschtum in Rio Grande do Sul (Brasilien) am Beispiel des Inspektionsberichts von Martin Braunschweig (1864-1908). Dissertação (Mestrado em História). Lateinamerika-Institut, Universidade Livre de Berlim, Berlin, 2006.

- O discurso protestante sobre a germanidade no Brasil: observações baseadas no periódico Der deutsche Ansiedler 1864-1908. Espaço Plural, v. 9, n. 19, p. 21-28, 2008.

- A constituição global da nação brasileira: questões de imigração nos anos 1930 e 1940. História, Ciências, Saúde - Manguinhos, v. 21, n. 1, p. 237-246, 2014a.

Auswanderung und gescheiterte Kolonialdiskurse: Deutschtum in Südbrasilien (1824-1941). Tese (Doutorado em História). LateinamerikaInstitut, Universidade Livre de Berlim, Berlin, 2014b.

SCHUSTER, Sven. „Fortschrittlich, zivilisiert, weiss": Ausstellungskultur, 
nationales Selbstbild und Rassediskurs in Brasilien, 1861-1929. Tese (Livre-Docência). Zentralinstitut für Lateinamerikastudien, Universidade Católica de Eichstätt, Eichstätt, 2012.

- Progreso, civilización y raza: historia patria y discurso racial en el Centenario de la Independencia en Brasil. In: SCHEUZGER, Stephan; SCHUSTER, Sven (eds.). Los Centenarios de la Independencia. Representaciones de la historia patria entre continuidad y cambio. Eichstätt: Zentralinstitut für Lateinamerika-Studien, 2013, p. 156-184.

- História, nação e raça no contexto da Exposição do Centenário em 1922. História, Ciências, Saúde - Manguinhos, v. 21, n. 1, p. 121134, 2014.

STANLEY, Ruth. Rüstungsmodernisierung durch Wissenschaftsmigration? Deutsche Rüstungsfachleute in Argentinien und Brasilien 1947-1963. Frankfurt: Vervuert, 1999.

THIES, Sebastian; KALTMEIER, Olaf. "Can the flap of a butterfly's wing in Brazil set off a tornado in Texas?". Transnationalization in the Americas and the field of identity politics. In: THIES, Sebastian; RAAB Josef (eds.). E pluribus unum? National and transnational identities in the Americas. Münster: LIT, 2008, p. 25-48.

TITTOR, Anne; LEUBOLT, Bernhard. Semi-periphere Sozialstaatlichkeit in Lateinamerika: Argentinien und Brasilien im historischen Vergleich. JEP

- Journal für Entwicklungspolitik, v. 24, n. 2, p. 116-41, 2008.

WÄTZOLD, Tim. Vom kaiserlichen Koch zum nationalen Koch: Ernährungsgeschichte des brasilianischen Kaiserreichs. Mettingen: Brasilienkunde-Verlag, 2011a.

Die Kochbücher des brasilianischen Kaiserreichs. Quellen zur nationalen Identität, materiellen Kultur und der Proklamierung der brasilianischen Küche 1840-1889. Vierteljahreschrift für Sozial- und Wirtschaftsgeschichte, v. 98, n. 4, p. 443-458, 2011b.

A proclamação da cozinha brasileira como parte do processo de formação da identidade nacional no império do Brasil (18221889). Belo Horizonte: TCS Editora, 2012.

. Europäische Ernährung in der Emigration. Das Beispiel Brasilien. In: LANGTHALER, Ernst; AMENDA, Lars (orgs.). Kulinarische Heimat und Fremde Ernährung und Migration im 19. und 20. Jahrhundert. Insbruck: Studienverlag, 2013a, p. 5-55.

- Nachwort und Einordnung der Memoiren in den Kontext der brasilianischen und Migrationsgeschichte. In: KNIESTEDT, Friedrich. Fuchsfeuerwild: Erinnerungen eines anarchistischen Auswanderers nach Rio Grande do Sul. Hamburg: Barrikade, 2013b, p. 204-216. 
WINK, Georg. Die Idee von Brasilien: eine kulturwissenschaftliche Untersuchung der Erzählung Brasilien als vorgestellte Gemeinschaft im Kontrast zu Hispanoamerika. Frankfurt: Peter Lang, 2009.

WOLFF, Martin. Die Stellung der ethnischen Presse im Prozess der Identitätskonstruktion ihrer Leser: eine inhaltsanalytische Untersuchung am Beispiel der Brasil-Post. Hamburg: Kovač, 2010.

ZACHER, Gerd. Die Gitarre im Schatten Heitor Villa-Lobos: Aspekte ihrer Bedeutung für die brasilianische Nationalmusik und für die Internationalisierung der Musik im 20. Jahrhundert. Tese (Doutorado em História da Música). Department Lehrerbildung und Musikpädagogik, Universidade de Potsdam, Potsdam, 2005.

ZOLLER, Rüdiger. Förderung, Quoten, Assimilierung: zur Einwanderungspolitik Brasiliens im 19. und 20. Jahrhundert. In: FISCHER, Thomas; GOSSEL, Daniel (eds.). Migration in internationaler Perspektive. München: Allitera, 2009, p. 121-142. 